\title{
URBAN TOURISM DEVELOPMENT \\ THROUGH LOW IMPACT DEVELOPMENT (LID) TOWARDS GREEN-TOURISM
}

\author{
WIWIK SETYANINGSIH \\ JURUSAN ARSITEKTUR, FAKULTAS TEKNIK \\ UnIVERsitas SEbElas MARET, SURAKarta \\ TRI YUNI ISWATI \\ JURUSAN ARSITEKTUR, FAKULTAS TEKNIK \\ UnIVERSITAS SEBELAS MARET, SURAKarTA \\ SRI YULIANI \\ JURUSAN ARSITEKTUR, FAKULTAS TEKNIK \\ UnIVERSITAS SEBELAS MARET, SURAKarTA \\ WIENDU NURYANTI \\ JURUSAN ARSITEKTUR, FAKULTAS TEKNIK \\ UNIVERSITAS GADJAH MADA, YOGYAKARTA \\ Budi Prayitno \\ JURUSAN ARSITEKTUR, FAKULTAS TEKNIK \\ UNIVERSITAS GADJAH MADA, YOGYAKARTA \\ AHMAD SARWADI \\ JURUSAN ARSITEKTUR, FAKULTAS TEKNIK \\ UNIVERSITAS GADJAH MADA, YOGYAKARTA
}

\begin{abstract}
World Tourism Organization(WTO), is one of theglobalissueson the international scene, becauseof theimpactof tourism activitieson the developmentand improvement ofthe economic, social, culturaland environmental qualityto the green-tourism. It is based with theSurakarta- city astourismandculturalcity towards the eco-city culture. The aim of the research, will focus on urban tourism andbuildformulationdevelopment through low impact development, in the realization ofgreen-tourism. It is based on explorative descriptive method combined with the mapping spatial of potential physical character (layout, building, and environment), included cultural, social and economic effects of tourism. The location of the research is Kauman urban settlement having a valuable unique and local potential and also its activities which are still exist right now. The result of the research, shows that the existence layout and environment of Kauman urban settlement has not been handled optimally. Moreover, it tends to lose its characteristics because it isn't protected. Therefore, structuringa tourist areathat emphasizes theuse ofnaturalandculturalresourceswisely byprioritizingcontinued existenceandlocal knowledgetominimize thenegativeimpacts oftourismon the environment. The concept isconceivedforallparties concernedagreedthattheapplication does notgive rise tocontradictionsbetweenthe variousinterests, useful asa guideto applysustainabledevelopment of urban tourism ispaying attention tothe environmentandlocalcommunities. The conclusion, that purposed to fulfill the formulated of urban tourism developmentpoliciesthat are environmentally friendlyandsustainable.
\end{abstract}

Keyword :urban tourism, low impact development and green- tourism

\section{PENDAHULUAN}

Suatu kawasan bersejarah dalam arsitektur perkotaan merupakan salah satu aset daya tarik wisata yang akan memberikan ikatan kesinambungan 
yang erat, antara masa lalu, masa kini dan masa mendatang. Hal tersebut, dilahirkan dengan gagasan serial vision, yaitu memadukan stating cultural significance dan heritage tourism dari karya arsitektur sebagai kampung wisata yang berkelanjutan.

Di sisi lain, pariwisata adalah isu global sebagai fokus perhatian dunia internasional melalui WTO (World Tourism Organization) dalam meningkatkan sektor ekonomi, sosial, budaya, dan dimensi lingkungan. Sampai saat ini pemerintah dan stakeholders terkait belum memperhatikan eksistensi kampung wisata yang memiliki domestikasi kearifan lokal sebagai aset berharga menuju green-tourism. Adapun pengembangan kampung wisata yang komprehensip dengan memadukan berbagai stakeholders terkait sangat berpengaruh terhadap peningkatan potensi kearifan lokal. Dalam kenyataan, masyarakat cenderung belum memperhatikan dan memahami keberadaan potensi kearifan lokal kampung wisata ini bisa dikemas sebagai aset green-tourism yang bernilai tinggi.

Penelitian ini dilakukan secara terpadu, didasarkan pada metode deskriptif eksploratif, paduan antara kajian potensi karakteristik kearifan lokal pada tata ruang kawasan, serta mapping social ekonomi budaya dan setting perilaku dengan pendekatan green-tourism. Hingga saat ini belum ada penelitian yang merekomendasikan rumusan model tentang konsep pengembangan kampung wisata sebagai perwujudan green-tourism. Oleh karena itu, penelitian ini sekaligus sebagai rumusan model pengembangan kampung wisata sebagai perwujudan green-tourism melalui eksplorasi potensi karakteristik domestikasi kearifan lokal (fisik dan non fisik), dengan variabel green-tourism.

Dengan demikian potensi domestikasi kearifan lokal kawasan dapat dilestarikan, dikembangkan dan dikemas menjadi aset green-tourism dalam pengembangan lampung wisata yang tepat, unik dan orisinil. Untuk itu unit kajian heritage arsitektur (UKHA) FT. Uns memiliki kewajiban moral untuk action peduli dengan mengawali penelitian ini sesuai dengan RIP dan road map uns tahun 2009-2020 tentang penyusunan konservasi, domestikasi, pelestarian.

Kampung kauman dikenal sebagai kampung para santri, di kampung ini tempat tinggal abdi dalem kraton yang bertugas mengurusi Masjid Besar Kauman dan sebagian besar abdi dalem mendirikan pesantren di rumahnya, karenanya kampung ini kemudian dikenal sebagai kampung santri. Selain kepiawaian mengelola masjid dan pesantren,, para abdi dalem ini memiliki keistimewaan dalam membatik. Karenanya Raja Surakarta mempercayakan pekerjaan membatik pada para abdi dalem 'kaum' ini. Membatik merupakan pekerjaan khusus pesanan dari raja dan bukan pekerjaan yang dianggap rutin melainkan pekerjaan yg istimewa karena sudah "dipilih" raja.

Dalam

perkembangannya kampung kauman berkembang menjadi kampung 'ketib' (abdi dalem pengurus masjid) sekaligus kampung batik (batik khusus untuk raja bukan batik untuk masyarakat umum). Sampai saat ini kampung ini masih dikenal sebagai kampung ketib/ santri karena karakter tersebut masih kental dirasakan di kampung ini.

Karena keunikannya kampung ini dikenal sebagai kampung wisata dan dalam perkembangannya banyak bermunculan bangunan-bangunan baru untuk mendukung fungsi kampung wisata ini, di lain hal munculnya banyak bangunan baru ini akan berdampak pada mutu lingkungan. Sejalan dengan program kota surakarta sebagai cultural city, maka pengembangan kawasan mengarah ke konsep green. Kawasan Kauman ini cocok untuk dijadikan pilot project sebagai kampung wisata dengan menerapkan sistem LID (Low Impact Development) untuk menjadikan Kawasan Kauman dengan keunikan dan kekhasan karakternya menjadi kawasan wisata yang berkonsep green. 
Tujuan dari penelitian ini adalah menentukan bagaimana konsep dan penerapan urban tourism development di Kauman dengan menerapkan LID menuju green.

Dengan memperhatikan UUDNo 5 Tahun 1992 tentang kepariwisataan, tim Kajian Heritage ArsitekturFT UNS sebagai pusat pembelajaran kebudayaan Jawa, Puspari UNS dan Badan Pelestarian Pusaka Indonesia serta Kementrian Pariwisata dan budaya tentang piagam pariwisata maka untuk menghindari pengelolaan kawasan wisata yang kurang memperhatikan potensi karakter domestikasi kearifan lokal sehingga merusak lingkungan diwujudkanlah Kampung Wisata Melalui Low Impact Development Sebagai Perwujudan Green Tourism.

\section{METODE PENELITIAN}

Penelitian dilakukan pada kawasan bersejarah kampung wisata Kauman Surakarta, didasarkan pada faktor potensi kearifan lokal yang mempunyai nilai sejarah. Kampung Kauman dipilih sebagai obyek penelitian karena terkait dengan keberadaan Karaton Surakarta sebagai simbol pusat kebudayaan yang masih eksis.

Penelitian diawali dengan pengumpulan data primer dan sekunder, selanjutnya dilakukan verifikasi dan pengolahan data. Pengumpulan data melalui: (a) survey dan wawancaradengan kuesioner untuk memetakankondisi sosial ekonomi dan budaya; (b) metode simak dan rujukan peta; serta(c) FGD dan PRA untuk menjaring kebutuhan dan aspirasi masyarakat. Pengolahan data menggunakan teknik analisis SWOT, statistik deskriptif dan analisis interaktif serta pendekatan latar belakang perilaku.

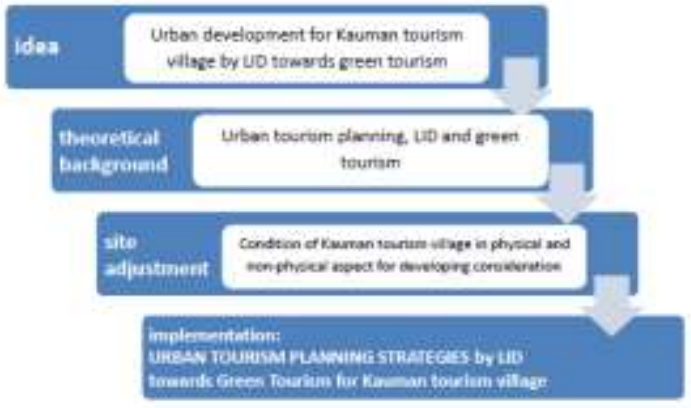

Gambar 1: Kerangka Pikir Penelitian

\section{HASIL DAN PEIMBAHASAN Pengembangan Kampung Wisata}

Kawasan Kauman secara keseluruhan merupakan kawasan konservasi dengan nilai Cultural Signifance yang cukup tinggi untuk dilestarikan.

- Historis : mempunyai keterikatan erat dengan pembentukan Karaton Kasunanan, yaitu sebagai hunian Abdi Dalem/Ulama Masjid Agung.

- Budaya : merupakan Kawasan yang dahulu dikenal sebagai Kawasan Kampung Abdi Dalem Masjid dan sering disebut sebagai kampung santri di tengah kota, dalam pen-siaran agama Islam harus dapat mengakulturasi antara kebudayaan dan kepercayaan Islam.

- Bangunan:utama kawasan Kauman sebagai permukiman atau hunian, bangunan rumah tinggal dengan penataan peruangan tradisional Jawa. Pembagian ruang private sampai publik menggunakan tingkatan hierarkiperbedaan split levellantai. Selain itu sebagai ulama abdi dalem karaton yang mampu secara finansial dapat membangun rumah yang megah dan indah.

$>$ Bangunan Lojen /Pamer batik

Bangunan toko/lojen juga merupakan bangunan tertutup tambahan. Fungsinyauntuk showroom pamer penjualan. Fungsinya sebagai ruang publik, sehingga gaya arsitektur yang diterapkan lebih unik dan lengkap dengan detail-detail.

Dari data yang telah dikemukakan, maka kawasan Kauman kampung wisata yang unik dan memiliki karakter khas yang harus dikembangkan dan dilestarikan mengingat terdapat nilai kultural dan kekentalan sejarah tinggi yang memiliki keterkaitan dengan sejarah pembentukan Kota Surakarta, khususnya Keraton Kasunanan.

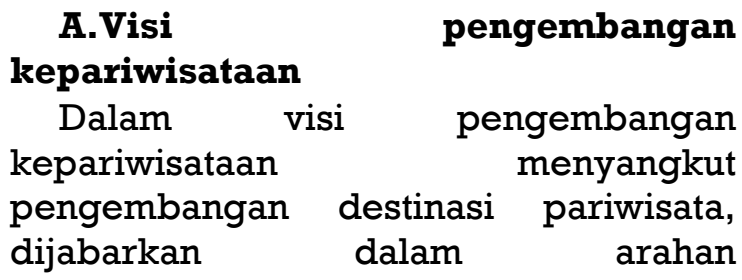


pengembangan pelibatan peran aktif masyarakat. Masyarakat memiliki peran dan posisi strategis yaitu sebagai subjek dan sebagai penerima manfaat pengembangan, merupakan pemangku kepentingan dalam pengembangan pariwisata (Stupa, 2010).

Dengan demikian, gambaran tersebut diatas menunjukkan bahwa masih banyak hal yang harus dilakukan untuk meningkatkan kemampuan dan kapasitas keikutsertan menyarakat lokal sehingga memiliki peran dan akses yang kuat untuk dapat berkiprah lebih besar dalam berbagai usaha pengembangan kepariwisataan di wilayahnya masingmasing.

\section{B.Kampung Kota}

Suhartanti (2000), mengatakan bahwa ciri kehidupan Indonesia bersifat khas, yaitupermukiman harus mencerminkan adanya hidup kekeluargaan, tingkat derajat yang sepadan, kerukunan beragama dan mendorong terwujudnya kegotong-royongan serta kemanfaatan bersama. Dengan demikian bahwa karakter permukiman tersebut mendukung tumbuh berkembangnya kampung-kampung wisata di Surakarta.

Ada tiga komponen pokok sebagai tumpuan dasar perkembangan kampung kota (Akses; sumber daya (resource) dan motivasi (motivation), dengan tingkat kemampuan yang berbeda dari masingmasing komponen, maka akan memberikan bentukan atau fenomena yang berbeda pula pada kampung kota. Komponen tersebut adalah:

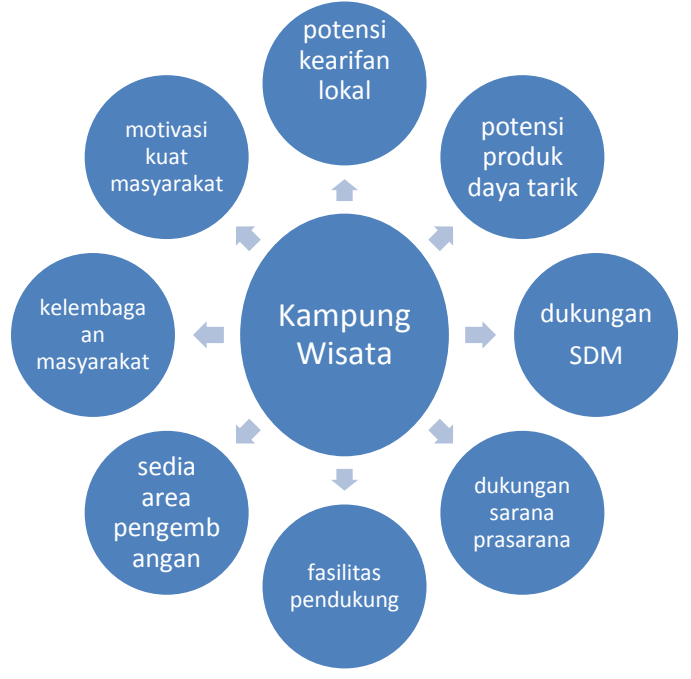

Gambar 2: Delapan Komponen Pembentuk Kampung Wisata

Sumber: Typologi kampung wisata, Wiwik, 2011

\section{C.Kampung Wisata}

Lane (1994) berpendapat bahwa kampung wisata merupakan serangkaian kegiatan pariwisata yang bertempat di kawasan kampung.

Gagasan mengenai kampung wisata bermula datang dari permintaan wisatawan untuk mengunjungi beberapa kampung yang dipandang memiliki keunikan tersendiri.Oleh karena suasana dan kehidupan serta tradisi masyarakat lokal dari kampung setempat merupakan aset utama dalam pembangunan kampung wisata (Bramwell, 1994).

Selanjutnya Lane (1994) mengatakan bahwa kampung wisata adalah serangkaian kegiatan pariwisata yang bertempat di kawasan kampung. Kampung wisata merupakan suatu bentuk pariwisata yang bertumpu pada objek dan daya tarik yang berupa kehidupan kampung dengan karakter keunikan khusus dalam masyarakat setempat termasuk budayanya, yang memiliki peluang untuk dijadikan komoditi bagi pengunjung/wisatawan, dan semua yang dihasilkan oleh kegiatan di dalam kampung tersebut akan dinikmati oleh masyarakat setempat secara langsung. Dukungan peran aktif partisipasi masyarakat sangat menentukan kelangsungan di dalam destinasi kampung wisata (Ganon, Agness, 1992). Ditambahkan dalam Setyaningsih (2013) found that the community needs to turn its attention to the loss of character of the buildings in Kauman, if the Kauman area is further developed considering only economic activities and not conservational issues. In the meantime, local communities in Kauman have not yet understood and realized why it is important to maintain local identity, and that unique value are an important asset.

Dengan demikian, maka kampung wisata merupakan salah satu bentuk pengembangan produk yang cukup signifikan di dalam mengurangi angka kemiskinan di perkampungan kota. Melalui green-tourism masyarakat lokal dilibatkan dalam kegiatan pariwisata 
yang ada.Selanjutnya, masyarakat lokal diharapkan dapat ikut merasakan dan memperoleh manfaat dari pengembangan kegiatan pariwisata.Tumbuh kembangnya destinasi wisata dapat menjadikan kampung wisata ini memiliki kriteria dan faktor pendukung dalam pengembangan kampung wisata (Greffe, X. 1994; Gannon, A. 1994; RTBL Kampung Baluwarti, 2010).

Dari teori-teori kampung, kampung kota dan rural-tourism, dapat disimpulkan bahwa kampung wisata adalah suatu bentuk pariwisata yang bertumpu pada potensi kearifan lokal obyek dan daya tarik dari kehidupan kampung dengan karakter keunikan khusus masyarakat lokal (fisik dan non fisik), yang memiliki peluang untuk dijadikan aset komoditi bagi pengunjung atau wisatawan untuk menikmati, dan semua yang dihasilkan oleh kegiatan kampung akan bermanfaat bagi masyarakat lokal.

\section{Low impact development (LID)}

Perubahan tata guna lahan karena pengembangan pemukiman akan berakibat pada berkurangnya daerah peresapan dan menaikkan laju aliran permukaan. Low Impact Development (LID), merupakan konsep pengelolaan skala kecil dari suatu sistem drainase air hujan pada kawasan permukiman. LID direncanakan mampu mengendalikan tinggi muka air yang akan dilepas ke daerah hilir serta memelihara aliran dasar (base flow) dan menyaring limbah dari daerah pemukiman. Teknik LID merupakan alat yang sangat baik untuk membantu melindungi menjaga keseimbangan alam secara berkesinambungan (Suseno, D. 2010 dalam Hermono, 2011)).

Beberapa penerapan LID :" Bioretention or rain garden, saluran rumput, "filter strip," dan perkerasan jalan yang "permeable".

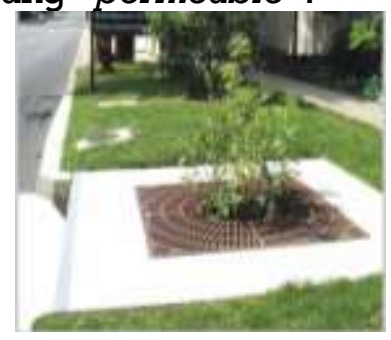

Gambar 3. Penerapan filter strip pada ruang terbuka

Selanjutnya dalam pengembangan kawasan kampung wisata menuju perencanaan culture- city, beberapa hal yang harus diperhatikan dalam penanganan lingkungan (menjaga, melindungi dan melestarikan keberadaan dan kondisi alam dan lingkungan dan menjadi bagian penting dari kawasan perencanaan); recycling, yaitu penggunaan teknologi, behavior/ perilaku masyarakat dan perencanaan yang memungkinkan untuk mengolah kembali hasil buangan menjadi material yang bisa dimanfaatkan kembali dan tidak mencemari atau berdampak buruk terhadap lingkungan; sustainability, pembangunan yang berkelanjutan yang mempunyai visi dan misi untuk jangka panjang.

Harmoni dengan lingkungan tidak saja terkait dengan keselarasan dan keseimbangan pemanfaatan lahan, namun juga dalam perencanaan fisik fasilitas yang mampu mengadaptasi karakter lokal baik secara fisik alam maupun budaya. Oleh karena itu, agar pengembangan kawasan dapat sejalan dengan prinsip-prinsip tersebut di atas, serta memperkuat citra kawasan yang berwawasan lingkungan sebagai salah satu nilai kompetitif kawasan, maka panduan (guidelines) perencanaan perlu dibuat sebagai acuan dasar pengembangan fasilitas dan kegiatan di kawasan tersebut.

Dari diskripsi tersebut di atas, dapat dipahami bahwa pembangunan berkelanjutan tergantung pada 3 elemen dasar yaitu: ecological integrity : lingkungan alam, yang akan terwujud jika masyarakat (baik secara individu maupun berkelompok) hidup selaras dengan lingkungan alam; economic security : pembangunan ekonomi, untuk mencapai tingkat, yang dapat mengontrol bahwa masyarakat (secara individu dan kelompok) dapat hidup dengan kondisi sosial ekonomi mereka sendiri, Democracy: pembangunan yang bertumpu pada masyarakat, kan tercipta karena partisipasi masyarakat (Pirages, 1996). 


\section{Green-tourism}

Adapun istilah green-tourism, muncul dalam WTO di Bali (dideskripsikan sebagai pembangunan pariwisata yang ramah danlestari, tidak disertai dengan dampak negatif terhadap lingkungan (fisik dan non fisik). Ditambahkan bahwa keberhasilan pembangunan pariwisata berbasis green-tourism amat ditentukan oleh kualitas lingkungan alam maupun budaya perilaku masyarakat, keduanya merupakan modal utama. Agar kelestarian dapat tercapai, pembangunan pariwisata harus senantiasa memperhatikan tercapainya keharmonisan antara kebutuhan wisatawan, destinasi wisata, serta masyarakat lokal sebagai tuan rumah (Nuryanti, 2010).

Konsep green-tourism bertujuan untuk menjaga keserasian antara unsurunsurnya, seperti kebutuhan pembangunan pariwisata, kelestarian fungsi lingkungan alam, sosial dan budaya, mutu produk pariwisata, profesionalisme sumber daya manusia, serta kepuasan wisatawan. Berbagai unsur tersebut harus dijaga keseimbangannya sehingga tidak akan menimbulkan benturan antara satu unsur dengan lainnya. Hal ini merupakan konsep yang berwawasan tentang keberlanjutankawasan sebagai pembentuk dan pengelola kawasan wisata nantinya. Green-tourism dengan mengupayakan perubahan budaya sikap dalam menata lingkungan, dalam pola perilaku dan gaya hidup untuk mendukung keberlanjutan kawasan wisata, serta pembentukan sikap yang baru dari interaksi manusia terhadap kawasan wisata (Dasar-dasar greentourism, 2010).

Sebagai sebuah aktifitas yang kompleks dan memiliki banyak faset, green-tourism melingkupi environmenttermasuk tourism sebagai wahana pendidikan konservasi dan rekreasi yang tumbuh dan berkembang pesat, dengan menampilkan otentisitas perilaku masyarakat lokal dan berbagai keunikan yang dimiliki, sehingga terjalin komunikasi yang dibangun melalui kegiatan interpretasi dan apresiasi terhadap potensi kearifan lokal.
Dari deskripsi di atas dapat disimpulkan bahwa tumbuh berkembangnya kampung wisata menuju green-tourism, haruslah memenuhi beberapa kriteria diantaranya: eksistensi kampung wisata, lokasi harus memiliki potensi daya tarik kearifan lokal yang khas, serta ada motivasi kuat dari masyarakat lokal untuk menciptakan kreativitas dalam green-tourism dengan meminimalkan dampak negatip menuju green tourism harus ada antusias pengembangan komunitas serta memiliki system kolaborasi kemitraan yang berlanjut diantara pemerintah, swasta dan masyarakat lokal sebagai motor penggeraknya.

Ditambahkan dalam City of Gold Coast, pada dasarnya terdapat 9 (sembilan) prinsip adaptasi dalam pembangunan berkelanjutan yang harus dilaksanakan oleh seluruh aktor pembangunan: (1) Menghormati dan memelihara komunitas kehidupan; (2)Memperbaiki kualitas hidup manusia; (3) Melestarikan daya hidup dan keragaman bumi; (4) Menghindari pemborosan sumber-sumber daya yang tidak terbarukan; (5) Berusaha tidak melampaui kapasitas daya dukung bumi; (6) Mengubah sikap dan gaya hidup orang per orang; (7) Mendukung kreatifitas masyarakat untuk memelihara lingkungan sendiri; (8) Menyediakan kerangka kerja menyeluruh untuk memadukan upaya pembangunan; dan pelestarian; (9) Menciptakan kerjasama global.

Urban

Systemgunamempertegas

Linkage

struktur dan tata ruang kawasan bersejarah Kampung Wisata Kauman melalui pengaturan urban landscape design berkonsep 'garden city'.

Penegasan struktur kerangka kawasan (urban structure) dapat dipertegas dengan kombinasi hijau sepanjang jalan/green belt structure, RTHdi ruang/space/jalan yang dilalui green belt area (Jl. Trisula, Jl, Wijaya Kusuma, Jl. Kalimosodo).

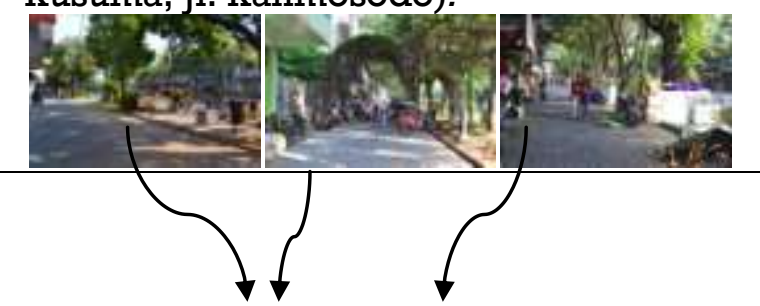




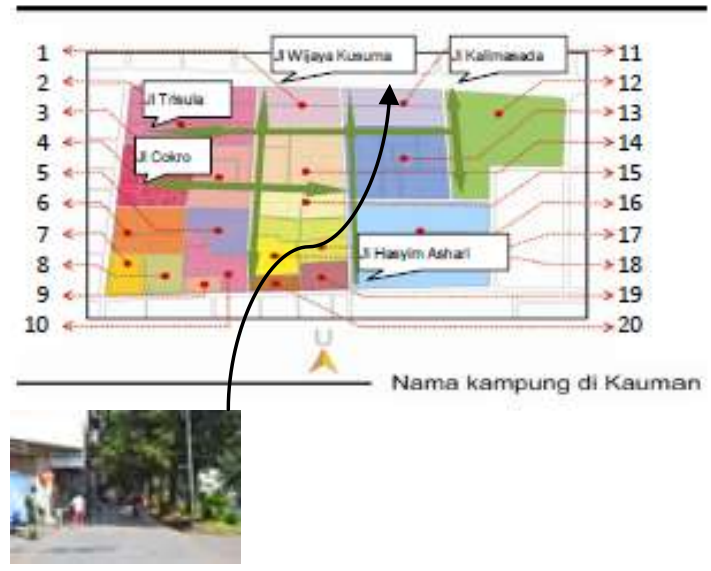

Gambar 4: Lima Jalan Utama Kauman Dan Kampung Kauman

(sumber: Wiwik 2013)

$\begin{array}{ll}\text { 1. Ketibimanan } & \text { 11. Sutomenggalan } \\ \text { 2. Semenan } & \text { 12. Keplekan } \\ \text { 3. Trayeman } & \text { 13. Pengulon } \\ \text { 4. Winongan } & \text { 14. Berasan } \\ \text { 5. Cendanan } & \text { 15. Gontoran } \\ \text { 6. Ketibanoman } & \text { 16. Gedang selirang } \\ \text { 7. Gebangsan } & \text { 17. Modinan } \\ \text { 8. Gerjen } & \text { 18. Kertowikaran } \\ \text { 9. Kintiran } & \text { 19. Baladan } \\ \text { 10. Blodiran } & \text { 20. Kambyahan }\end{array}$

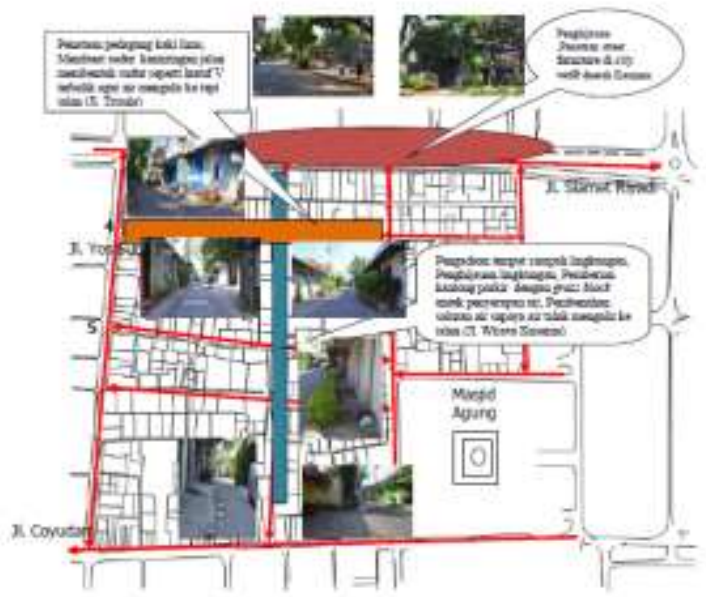

Gambar 5. Penerapan LID dan GREEN di kawasan Kauman untuk menuju Kauman sebagai Kawasan Wisata Berbasis LID dan Green

(sumber: Wiwik, 2013)

Selanjutnya dalam menunjang keberadaan Kawasan Bersejarah Kauman sbg Kampung Wisata yg Berkonsep Lid Menuju Green Tourism , maka ada beberapa kriteria yang harus diperhatikan,

1. Orientasi dan Main/Side Entrance

Pemilihan main entrance didasari pada zone yang memungkinkan yaitu area yang luas dan mudah dikenali yaitu ditepi jl Slamet Riyadi dan berada di area city walk.

Pertimbangan pemilihan pencapaian ke dalam kampung wisata Kauman:

Main Entrance :

Pemilihan main entrance berdasar pada alasan kemudahan untuk menemukan, kemudahan sirkulasi,, kemudahan untuk mencapai, kemudahan untuk mengingat, kemudahan dikenali. Karena itu dipilih main entrance dari arah $\mathrm{Jl}$ Slamet Riyadi karena berada di tepi jalan utama.

2. Sirkulasi ke dalam

Jalan jalan utama untuk memasuki kawasan Kauman harus jelas. Setelah itu ditentukan jalan jalan sekenderi. Kondisi fisik atau eksisting jalan baik lebar jalan maupun material jalan harus dipetakan. Kenyamanan pengguna diutamakan supaya mudah mengakses dan menentukan pilihan jalur jalan mana yang dipilih.

3. Sirkulasidalam kawasan kampung wisata Kauman

Setelah memasuki kawasan Kauman maka hal yang perlu dipikirkan selanjutnya adalah cara pencapaian ke masing-masing bangunan di Kawasan Kauman. Kejelasan dan kemudahan baik pengguna roda dua roda empat maupun pejalan kaki menjadi penting. Letak kantungkantung parkir harus jelas. Kenyamanan pedestrian diutamakan.

4. Pedestrian Ways dan Penanda Jalan/ signage

Untuk memudahkan dan membuat nyaman pengguna jalan dibuat penanda jalan sehingga memperkecil kemungkinan wisatawan tersesat dan memudahkan untuk mencapai tujuan.

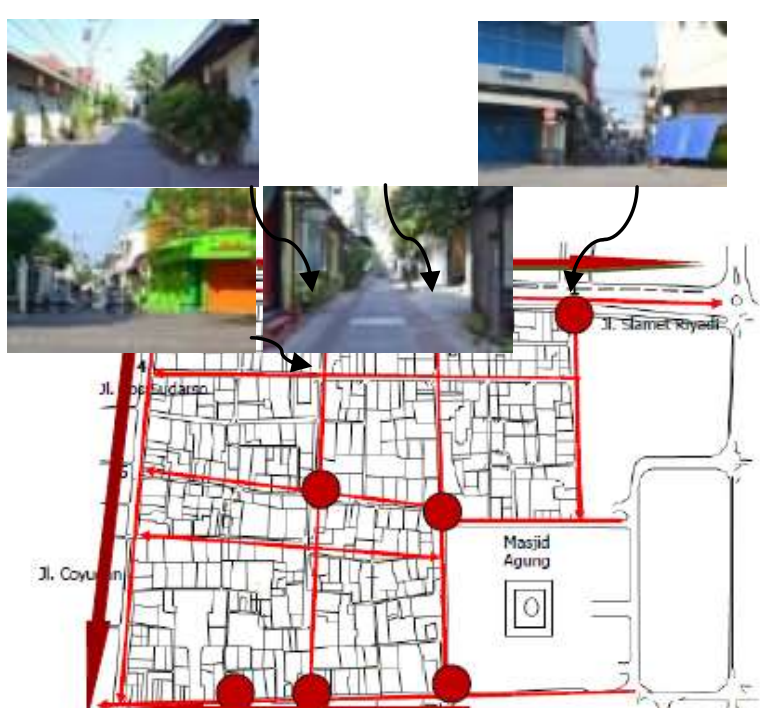


Gambar 6Orientasi dan Main/ Side Entrance Sumber: Analisis Wiwik, 2010

\section{Perkerasan}

Perkerasan bertujuan sebagai area sirkulasi dan plasa, material dipilih yang mudah dibersihkan, berbentuk pola geometri. Selain untuk tujuan ${ }^{e_{\text {itu }}}$ juga untuk pengarah/ penunjuk jalan

Beberapa faktor pendukung untuk kampung wisata Kauman adalah :

a. Atractive street

Mendesain koridor jalan agar tercipta area yang atraktif, pola jalan yang bervariasi untuk memperoleh kenyamanan dan keamanan

Signage didesain untuk mendapatkan kemudahan dan kenyamanan (keteduhan, kantong istirahat dan pedagang kaki lima).

Fasade bangunan didesain dengan konsep modern namun bangunan asli dipertahankan sesuai dengan aslinya. Untuk menyatukannya dipilih material bangunan yang tepat sehingga memperkuat kearifan lokalnya..

b. Social event

Merupakan sarana berkumpul warga dan menjadi ajang pementasan warga, bisa berupa berbagai macam jenis kegiatan kampung wisata .

c. Open stage

Merupakan ruang terbuka bisa berupa persimpangan jalan atau taman yang bisa digunakan sebagai ruang komunal untuk berinteraksi antar warga. d. Urban furniture
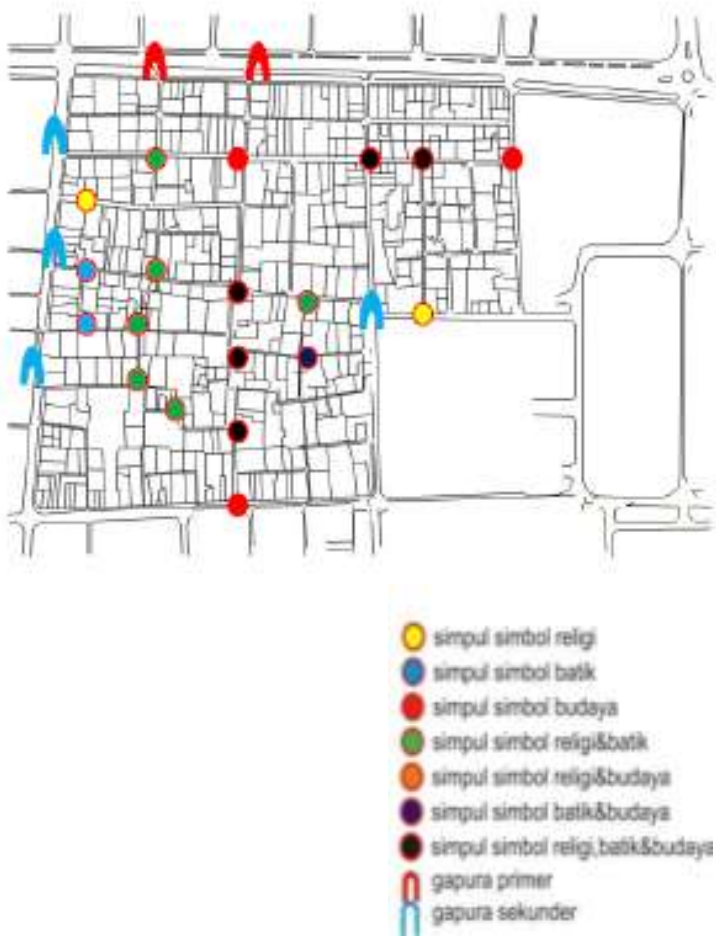

Gambar7. Simpul Perjalanan Kampung Wisata Kauman

\section{KESIMPULAN}

Dari hasil pembahasan di atas dapat disimpulkan bahwa penerapan LID dikawasan Kauman dapat juga diterapkan di Kampung kota lainnya yang setara semisal Kampung Laweyan, Kampung Sondakan serta kampungkampung yang memiliki karakter kedominasian.

Untuk mencapai Kauman sebagai kawasan wisata yang mengacu pada konsep green beberapa cara dibawah ini harus dilakukan:

Penerapan LID low impact development dengan mewadahi saluran drainase di sepanjang tepi jalan, membuat kemiringan jalan dari tengah kearah samping dan miring secara memanjang, membuat resapan air hujan, penggunaan grass block untuk area parkir dan ruang komunal, mengurangi jalan aspal sebaiknya menggunakan material jalan yang dapat menyerap air/ paving block.

Penerapan green design dengan membuat pergola di citywalk, membuat penghijauan di ruang parkir, membuat penghijauan di sepanjang tepi jalan, membuat penghijauan di area masuk kawasan Kauman, menyediakan tempat sampah yang menarik di sepanjang jalan 
di kawasan kauman, penataan pedagang kaki lima di semua area Kauman Mengelola street furniture agar nyaman digunakan dan tidak mengganggu pengguna jalan

\section{DAFTAR PUSTAKA}

Andi, S, Wiwik S, Yennel S. 2012. Review Penyusunan Master Plan Pembangunan Kebun Raya Cibinong, Jawa Baratberbasis Eco Green Environment, Laporan kegiatan Kementerian Pekerjaan Umum, Jakarta.

Anonim, 2010,Dasar-dasar Greentourism, Kementerian Pariwisata, Jakarta

Anonim, 2009, RTBL Baluwarti Surakarta, DTRK Surakarta

Hermono, Setyaningsih, 2011. Pengendalian Aliran Permukaan Akibat Pengembangan Pemukiman dengan Konsep Low Impact Development (LID), Journal Arsitektura, ISSN 1693-3680, Vol.09. N0.2. Th. 2011, Arsitektur FT UNS Surakarta.

JatmikaA., Wiwik S, Yennel S. 2011. Pengembangan Kampus Kementerian Pekerjaan Umum Berbasis Green Design, Green InfrastuctureDan Green Operasional \& Maintenance, Masterplan Pengembangan Kampus Kementerian Pekerjaan Umum, Jakarta.

Kostof, 1991, Harmony And Hierarchy In Javanese Kampung. Asian Studies Association Of Australia, Souttheas Asia Publications Series No. 11 Singapura Oxford, Dan New York: Oxford University Press.

LANE, B. 1994. SUSTAINABLE RURAL TOURISM STRATEGIES: A TOOL FOR DEVELOPMENT AND CONSERVATION. JOURNAL OF SUSTAINABLE TOURISM, 2(1), 102111.

Mcintosh, A. J., \&Goeldner, 1986.Affirming Authenticity, Consuming Cultural Heritage.Annals of Tourism Research, 26, 589-612.

Mikklesen.2001. Metode Penelitian Partisipatoris dan Upaya-Upaya Pemberdayaan.Yayasan Obor. Jakarta.
Miles MB, Huberman AM, 1994, Qualitative Data Analysis: An Expanded Sourcebook, Sage: Thousand Oaks

NURYANTI, W. 2010, INTERNATIONAL SEMINAR, WISDOM 2010, LOCAL WISDOM INSPIRING GLOBAL SOLUTIONS, WORLD CONFERENCE ON CULTURE, EDUCATION AND SCIENCE, UGM YOGYAKARTA, DECEMBER 5- 8TH, 2010.

Nuryanti. 2005. Heritage And Postmodern. Annal of Tourism Research Vol.32 Number 1. Britain

Suseno Darsono, Pembangunan Berdampak Kecil Pada Sistim Drainasi Kota.Jurusan Sipil Fakultas Teknik Universitas Diponegoro

Suhartanti.2000. Penataan Kampung Baru Kawasan Kedungdoro Surabaya.Skripsi Tidak Diterbitkan. Malang: Universitas Brawijaya, 2000

Setyaningsih, W. 2013. The Kauman Settlement in Surakarta and the Typology of the Rumah Ketib, Insular Diversity, Architecture-CultureIdentity in Indonesia, Published by Institute for Comparative Research in Architecture IVA-ICRA, Vienna, Austria.

Setyaningsih, W. Model Pengembangan Kampung Wisata melalui Peran Masyarakat dalam Pengembangan Wisata Religi dan Wisata Budaya Kauman, Hasil Penelitian Dikti.

Setyaningsih, W. Model Pelestarian Kawasan Bersejarah Melalui Peningkatan Peran dan Interpretasi Masyarakat Sebagai Alternatip Pengembangan Wisata Budaya Yang Berkelanjutan, Hasil Penelitian Dikti.

Setyaningsih, W. Study Evaluasi Teknik Heritage Pelestarian Kawasan Wisata Pengging. Boyolali.PMU-PU. Jakarta

Hermono S. Budinetro, Wiwik Setyaningsih;Pengendalian Aliran Permukaan Akibat Pengembangan Pemukiman Dengan Konsep Low Impact Development (LID) 